\title{
Viewpoint
}

\section{A comment on Baker and Benn 2001: 'Assigning pupils to tutor groups in a comprehensive school'}

Baker and Benn's paper ${ }^{1}$ describes an interesting practical application of an allocation heuristic. They are wrong, however, when they state that this problem has not attracted the attention of researchers, as there are several papers dealing with such situations.

Mingers and O'Brien ${ }^{2,3}$ addressed an almost identical problem in assigning university students to work groups in an equitable way - they termed this the 'equitable partitioning problem'. The only difference is that Baker and Benn have the additional constraint of respecting prior friendship groups. We will incorporate this in our own algorithm and report on comparative results in the future.

Other research in this area includes Beheshtian-Ardekani and Mahmood, ${ }^{4}$ Miyaji et al, ${ }^{5}$ Muller, ${ }^{6}$ Donohue and Fox, ${ }^{7}$ Weitz and Lakshminarayanan. ${ }^{8,9}$

\section{References}

1 Baker BM and Benn C (2001). Assigning pupils to tutor groups in a comprehensive school. J Opl Res Soc 52: 623-629

2 Mingers J and O'Brien F (1995). Creating student groups with similar characteristics: a heuristic approach. Omega 23: 313-321.

3 O'Brien F and Mingers J (1997). A heuristic algorithm for the equitable partitioning problem. Omega 25: 215-223.

4 Beheshtian-Ardekani M and Mahmood MA (1986). Development and validation of a tool for assigning students to groups for class projects. Decision Sci 17: 92-113.
5 Miyaji I, Ohno K and Mine H (1988). Solution method for partitioning students into groups. Eur J Opl Res 33: 82-90.

6 Muller T (1989). Assigning students to groups for class projects. Decision Sci 20: 623-634.

7 Donohue J and Fox JB (1993). An investigation into the PeopleSequential Heuristic method. Decision Sci 24: 493-508.

8 Weitz R and Lakshminarayanan S (1997). An empirical comparison of heuristic and graph theoretic methods for creating maximally diverse groups. Omega 25: 473-482.

9 Weitz R and Lakshminarayanan S (1998). An empirical comparison of heuristic methods for creating maximally diverse groups. J Opl Res Soc 49: 635-646.

University of Warwick

JC Mingers and F O’Brien

\section{Response to Mingers and O'Brien}

Our thanks go to $\mathrm{J}$ Mingers and $\mathrm{F}$ O'Brien for drawing attention to their work. It is pleasing to see that the report of our case study will be influencing future development of their algorithm.

Coventry University

BM Baker

Finham Park Comprehensive School,

C Benn 